GU J Sci, Part C, 6(2): 374-384 (2018)

Gazi Üniversitesi
Fen Bilimleri Dergisi
PART C: TASARIM VE TEKNOLOJI
dergipark.gov.tr/http-gujsc-gazi-edu-tr

\title{
Nikel Ara Katman Kullanılarak İnsörtlü Toz Enjeksiyon Kalıplama Yöntemiyle WC-Co/HSS Kompozit Parça Üretiminin Araştırılması
}

\author{
Harun KOÇAK ${ }^{1, *}$, Kamran SAMET ${ }^{2}$, Oğuz YILMAZ², Çetin KARATAŞ² \\ ${ }^{I}$ Selçuk Üniversitesi, Cihanbeyli MYO, Makine Ve Metal Teknolojileri Bölümü, Cihanbeyli/KONYA \\ ${ }^{2}$ Gazi Üniversitesi, Teknoloji Fak., Imalat Mühendisliği, 06500, Teknikokullar, Ankara
}

$\ddot{O} \mathbf{z}$

Makale Bilgisi

Bașvuru: 19/09/2018

Düzeltme: 07/01/2018

Kabul: $18 / 01 / 2018$

Anahtar Kelimeler

ITEK

$W C-C o$

HSS

Keywords

IPIM

WC-Co

HSS
Toz enjeksiyon kalıplama yöntemiyle yüksek yoğunluklu metal, seramik, kompozit ve intermetal malzemelerden geometrik hassasiyete sahip küçük parçaların üretimi yapılabilmektedir. Daha büyük parçalar üretebilmek için insört adı verilen hazır parça kalıp içerisine yerleştirilerek üzerine toz enjeksiyon kalıplama yapılmaktadır. Bu yöntem insörtlü toz enjeksiyon kalıplama (ITTEK) olarak adlandırılmaktadır. İTEK yöntemi, daha büyük parçaların üretiminde kullanılmasının yanında farklı malzemelerden parça üretimi için de kullanılabilecek bir yöntemdir. $\mathrm{Bu}$ çalışmada nikel ara katman kullanılarak İTEK yöntemiyle WC-Co/HSS kompozit parça üretimi araştırılmıștır. Sinterleme sıcaklığının ve süresinin etkileri, besleme stokunda meydana gelen boyutsal çekme ve ara bölgedeki kesme dayanımı incelenmiştir. Sıcaklık ve süre arttıkça enjekte kısmın boyutsal çekme miktarı artmaktadır. En yüksek boyutsal çekme oranı, $1250{ }^{\circ} \mathrm{C}$ ve 360 dakikada sinterlenen numunelerde $\% 15,92$ olarak ölçülmüştür. Deneylerde en yüksek kesme mukavemeti $1200^{\circ} \mathrm{C}$ sicaklık ve 120 dakika sinterleme süresiyle, $100 \mu \mathrm{m} \mathrm{Ni}$ ara katman kullanılan numunede $114 \mathrm{MPa}$ olarak elde edilmiştir.

\section{Investigation Of Composite Part Production From WC-Co/HSS Using Nickel Interlayer By Inserted Powder Injection Molding Method}

\begin{abstract}
It is possible to produce small parts with geometric precision from high density metal, ceramic, composite and intermetal materials by powder injection molding (PIM) methot. In order to produce bigger parts, the prepared component called the insert is placed in the mold and powder injection molding is carried out on it. This method is named inserted powder injection molding (IPIM). The IPIM is a good method that can be used for the production of parts from different materials as well as for the production of larger parts. In this study, part production was investigated using HSS insert, Ni interlayer and WC-Co (9\%) feedstock by IPIM method. The effects of sintering temperature and duration, linear shrinkage in the feedstock and shear strength between the two materials were examined. The linear shrinkage ratio increases with increasing temperature and time, and the maximum linear shrinkage at the injected part at 1250 ${ }^{\circ} \mathrm{C}$ for 360 minutes is found as \%15.92. At $1200^{\circ} \mathrm{C}$ temperature and 120 minutes of sintering time, the highest shear strength obtained with the sample using $100 \mu \mathrm{m} \mathrm{Ni}$ interlayer is 114 MPa.
\end{abstract}

\section{GİRIŞ (INTRODUCTION)}

Toz enjeksiyon kalıplama yönteminde (TEK) toz halindeki metal ve seramik malzemeler bağlayıcıyla karıştırılıp akışkanlık kazandırılarak enjeksiyon makinesi yardımıyla metal kalıp içerisine aktarılır. Kalıp içerisinde bağlayıcı katılaşarak ham mamul elde edilir. Sonraki aşamada bağlayıcı bileşenlerinden bir kısmı çözündürmeyle alınır ve parça sinterlenir. Sinterleme esnasında parça içerisindeki bağlayıcı tamamen giderilirken tozların birbirine difüzyonu sağlanarak parça üretimi gerçekleştirilmiş olur [1-4]. 
TEK yöntemiyle genellikle küçük parçalar üretilmektedir. Parça boyutu arttıkça bağlayıcı giderme işlemi zorlaşmakta ve maliyet artmaktadır. Bu nedenle TEK yöntemiyle büyük parçaların üretilebilmesi için İTEK yöntemi geliştirilmiştir [2,5]. İnsört adı verilen hazır bir parça kalıp içerisine yerleştirilerek üzerine besleme stoku enjekte edilmektedir. Kullanılan insört sayesinde enjekte kısmın et kalınlığı azaltılarak büyük parçaların İTEK yöntemiyle üretimi yapılabilmektedir. İnsört ve enjekte kısımda metalik olan aynı malzemeler kullanıldığında sağlam bir birleşme elde etmek mümkündür. Ancak metal insört ile seramik besleme stoğu gibi farklı malzemeler kullanılarak yapılan parça üretiminde malzemelerin fiziksel ve kimyasal özellikleri ara kesitte istenilen mukavemet değerinin elde edilmesini önemli ölçüde etkilemektedir. $\mathrm{Bu}$ yüzden seramik ve metal malzemelerin farklı özelliklerinden aynı anda yararlanmak ve bu malzemelerle nitelikli parçalar üretebilmek için bu malzemeleri birleştirmeyi mümkün kılacak yeni yöntemlerin araştırılması gerekmektedir.

Endüstriyel uygulamalar ve araştırmalar incelendiğinde sertlik, termal kararlılık ve aşınma dayanımlarının iyi olması bakımından metal malzemelerle birlikte sementit karbürler yaygın olarak kullanılmaktadır [6]. Ancak karbürler tek başlarına kırılgandırlar ve yüksek sıcaklıkta sinterlenmektedir. Sinterleme sıcaklığını düşürmek ve kırılganlığını azaltmak için kobalt ile sıvı faz sinterleme yapılarak üretilirler. Bu nedenle mekanik özellikleri kobalt miktarına ve tane boyutuna bağlı olarak değişmektedir [7,8]. Kobalt miktarına bağlı olarak sementit karbürlerin toklukları iyileştirilebilmekte, fakat elde edilen tokluk bazı uygulamalar için yeterli olmamaktadır. Bu durumda sementit karbürler metal malzemelerle özellikle çeliklerle birleştirilerek kullanılmaktadır. Genel olarak karbürler lehimleme [9], difüzyon kaynağı [10], lazer kaynağı ve mekanik kilitleme [11] gibi yöntemlerle çelik malzemelere birleştirilmektedir.

Yukarıdaki yöntemlerin çoğu için farklı iki malzemeden parça üretilirken malzemelerin fiziksel ve kimyasal özelliklerinin birbirine yakın olması gerektiği belirtilmektedir [12,13]. Ancak sementit karbür ve metal malzemelerin fiziksel ve kimyasal özellikleri birbirinden çok farklıdır. Bu farklılık malzemelerin birlikte sinterlenme davranışlarını etkilemekte ve malzeme çifti arasında hataların ortaya çıkmasına neden olmaktadır [14,15]. Bu nedenle farklı özelliklere sahip malzemelerin birleştirilmesi veya bu malzemelerden parça üretilmesi zorlaşmaktadır. Bu konuda yapılan bazı çalışmalarda sementit karbür ve metal malzemeler arasına ara katman uygulandığında malzeme özelliklerinden kaynaklanan sorunların azaldığı belirtilmektedir [16,17]. Sementit karbür malzemeler çoğunlukla çeliklerle birleştirilmeye çalışılmakta ve termal özellikleri çeliğe yakın olması nedeniyle ara katman olarak genellikle nikel kullanılmaktadır $[16,18]$. Bununla birlikte ara katman kullanılarak sinterleme esnasında malzemelerin birleştirilebilmesi için ara bölgede yeterli düzeyde basıncın da olması gerekmektedir [19]. İTEK yönteminde ara bölgede oluşan basınç, boyutsal çekme ve termal genleşme sonucu ortaya çıktığı için bu özelliklerden yararlanılarak malzeme çifti arasındaki basınç miktarı arttırılabilmektedir [20].

Bu çalışmada, sertlik ve tokluk gibi zıt özelliklere sahip nitelikli parçanın İTEK yöntemiyle üretimi araştırılmıştır. Üretilecek olan parçanın iç kısmında hazır HSS insört, dış kısmında ise WC-\%9Co besleme stoku kullanılmıştır. Farklı özelliklere sahip bu malzemeleri sinterleme esnasında daha iyi birleştirebilmek amacıyla HSS insörtlerin üzeri elektrolizle Ni kaplanmıştır. Daha sonra insört, kalıp içerisine yerleştirilerek üzerine $\mathrm{WC}-\% 9 \mathrm{Co}$ besleme stoku enjekte edilmiştir. Elde edilen test numunelerine, bağlayıcı giderme ve sinterleme işlemleri uygulanmıştır. Sinterleme sıcaklığının ve süresinin etkileri, besleme stokunda meydana gelen boyutsal çekme ve ara bölgedeki kesme dayanımı incelenmiştir.

\section{MALZEME VE METOT (MATERIALS AND METHOD)}

\subsection{Malzeme (Material)}

Üretilecek parçanın iç kısımda M2 tipi HSS (1.3343) insört dış kısmında ise WC-Co(\%9) besleme stoku kullanılmıştır. Besleme stoku Ryer firmasından hazır olarak alınmıştır. İnsört ve besleme stoku arasında difüzyon düzeyini arttırabilmek için Ni ara katman kullanılmıştır. HSS malzemenin kimyasal içeriği Tablo 1'de, 1sıl özellikleri Tablo 2'de ve WC besleme stokunun kimyasal bileşimi Tablo 3'te verilmiştir. 
Ni elementinin, HSS insört ve besleme stoku içerisinde yer alan elementlerin difüzyon için önemli özellikleri Tablo 4'te verilmiştir.

Tablo 1. M2 HSS malzemenin kimyasal bileşimi (\%)

\begin{tabular}{|l|l|l|l|l|l|l|l|l|}
\hline C & Si & Mn & Cr & Mo & Ni & V & W & Co \\
\hline 0,9 & 0,25 & 0,3 & 4,10 & 5,0 & 0 & 1,8 & 6,40 & 0 \\
\hline
\end{tabular}

Tablo 2. M2 HSS malzemenin isll özellikleri

\begin{tabular}{|l|l|l|l|}
\hline $\begin{array}{l}\text { Is1l iletkenlik } \\
20^{\circ} \mathrm{C} \mathrm{de}\end{array}$ & $\begin{array}{l}\text { Özgül Is1 } \\
20^{\circ} \mathrm{C} \mathrm{de}\end{array}$ & Östenitlenme sıcaklığ1 & $\begin{array}{l}\text { Is1l genleşme } \\
100-700^{\circ} \mathrm{C}\end{array}$ \\
\hline $19 \mathrm{~W} /(\mathrm{m} . \mathrm{K})$ & $460 \mathrm{~J} /(\mathrm{kg} . \mathrm{K})$ & $1210^{\circ} \mathrm{C}$ & $11,5-12,910^{-6} \mathrm{~m} /(\mathrm{m} . \mathrm{K})$ \\
\hline
\end{tabular}

Tablo 3. WC-Co(\%9) besleme stokunun kimyasal bileşimi (\%)

\begin{tabular}{|l|c|c|c|c|c|c|c|c|}
\hline Elementler & $\mathrm{C}$ & $\mathrm{Cr}$ & $\mathrm{Fe}$ & $\mathrm{Mo}$ & $\mathrm{Ni}$ & $\mathrm{W}$ & $\mathrm{Co}$ & $\mathrm{O}$ \\
\hline Kütlece & 5,54 & 0,01 & 0,01 & 0,01 & 0,01 & Kalan & 8,94 & 0,05 \\
\hline
\end{tabular}

Tablo 4. Elementlerin difüzyon için gerekli özellikleri

\begin{tabular}{|c|c|c|c|c|c|c|c|}
\hline Elemellikler & $\begin{array}{l}\text { Ergime } \\
\text { S1caklığ } \\
\left({ }^{\circ} \mathrm{C}\right)\end{array}$ & $\begin{array}{l}\text { Kaynama } \\
\text { S1caklığ } \\
\left({ }^{\circ} \mathrm{C}\right)\end{array}$ & $\begin{array}{l}\text { Özgül } \\
\text { ağırlık } \\
\left(\mathrm{g} / \mathrm{cm}^{3}\right)\end{array}$ & $\begin{array}{l}\text { Atom } \\
\text { Yarıçap1 } 1 \\
(\mathrm{~nm})\end{array}$ & $\begin{array}{l}\text { Aktivasyon } \\
\text { enerjisi } \\
(\mathrm{kj} / \mathrm{mol})\end{array}$ & $\begin{array}{l}\text { Is1l } \\
\text { genleşme } \\
\left(10^{-6} /{ }^{\circ} \mathrm{C}\right)\end{array}$ & $\begin{array}{l}\text { Kafes } \\
\text { sistemi }\end{array}$ \\
\hline $\mathrm{Ni}$ & 1455 & 2730 & 8.9 & 0,125 & 298 & 13.4 & $\mathrm{YMK}$ \\
\hline $\mathrm{Co}$ & 1495 & 2900 & 8.9 & 0,125 & 292 & 13 & $\mathrm{SPH}$ \\
\hline $\mathrm{Fe}$ & 1539 & 2740 & 7.87 & 0,124 & 239 & 11.8 & $\mathrm{HMK}$ \\
\hline $\mathrm{Cr}$ & 1890 & 2500 & 7.19 & 0,128 & 318 & 4.9 & $\mathrm{HMK}$ \\
\hline $\mathrm{Mo}$ & 2625 & 4800 & 10.2 & 0,140 & 418 & 4.8 & $\mathrm{HMK}$ \\
\hline
\end{tabular}

\section{2. İnsörtlerin Hazırlanması ve Ara Katman Uygulaması (Preparing Inserts and Applying the Interlayer)}

HSS malzemeden $6,3 \mathrm{~mm}$ çapında insörtler hazırlanarak üzerine elektrolitik kaplama yöntemiyle $\pm 3 \mu \mathrm{m}$ toleransla $25 \mu \mathrm{m}, 50 \mu \mathrm{m}$ ve $100 \mu \mathrm{m}$ Ni kaplanmıştır. Kaplama işleminde teknik döküm firmasından hazır olarak alınan Nikel kaplama banyosu kullanılmıştır. Kaplama şartları Tablo 5'te verilmiştir. Kaplama işlemi sonrası kaplama kalınlığı X-Ray ölçme cihazıyla çap yüzeyinden ölçülmüştür.

Tablo 5. Elektrolitik Ni kaplama şartları

\begin{tabular}{|c|c|c|c|c|}
\hline Anot & Banyo sıcaklığ1 & Voltaj & Akım yoğunluğu & Bekleme süresi \\
\hline Elektrolitik Nikel & $50-60{ }^{\circ} \mathrm{C}$ & $2,5-3 \mathrm{~V}$ & $4 \mathrm{~A} / \mathrm{dm}^{2}$ & $1 \mu \mathrm{m}$ için $2 \mathrm{dk}$ \\
\hline
\end{tabular}

\section{3. İnsörtlü Toz Enjeksiyon Kalıplama (Inserted Powder Injection Molding)}

Enjeksiyon işlemi için ARBURG Allrounder 220S enjeksiyon kalıplama tezgahı kullanılmıştır. M2 HSS çeliğinden hazırlanan insörtler kalıp içerisine yerleştirilerek üzerine besleme stoku enjekte edilmiştir (Şekil 1). Besleme stoku üretici firmanın tavsiye ettiği değerler dikkate alınarak çıkan ürünün durumuna 
göre optimum enjeksiyon parametreleri belirlenmiştir. Enjeksiyon işleminde kullanılan parametreler Tablo 6'da verilmiştir.

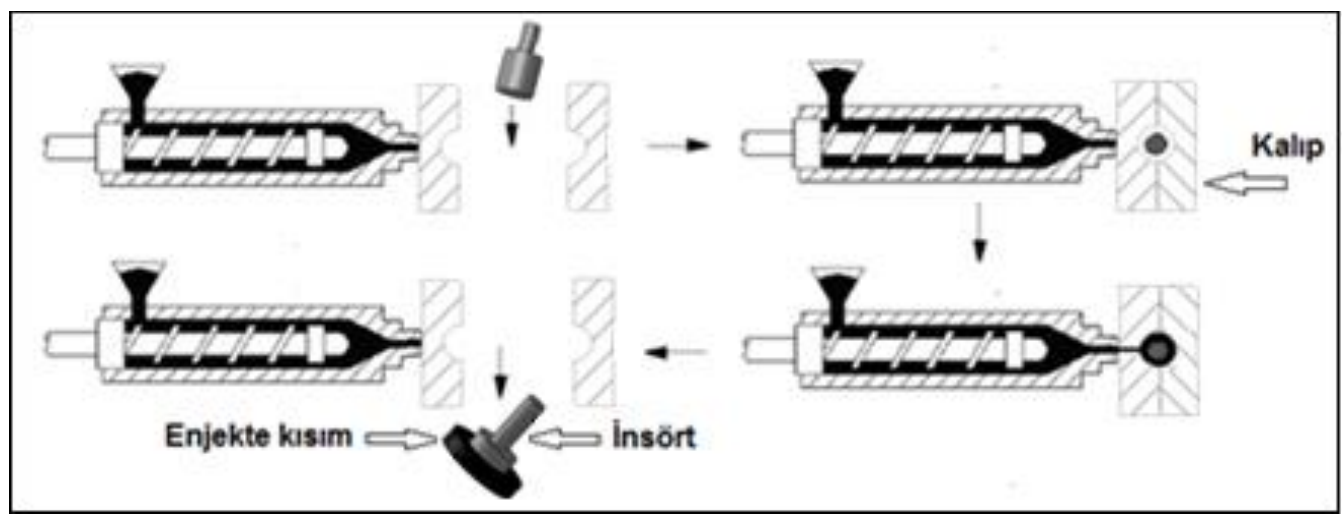

Şekil 1. Insörtlü toz enjeksiyon kalıplama (İTEK) işlemi

Tablo 6. Enjeksiyon parametreleri

\begin{tabular}{|c|c|c|c|c|}
\hline Enjeksiyon sıcaklığ & Enjeksiyon basıncı & Ütüleme basınc1 & Enjeksiyon hızı & Kalıp sıcaklı̆̆ \\
\hline $200{ }^{\circ} \mathrm{C}$ & $280 \mathrm{bar}$ & $80 \mathrm{bar}$ & $10 \mathrm{ccm} / \mathrm{s}$ & $60{ }^{\circ} \mathrm{C}$ \\
\hline
\end{tabular}

\subsection{Bağlayıcı Giderme ve Sinterleme işlemleri (Debinding and Sintering Processes)}

$60{ }^{\circ} \mathrm{C}$ 'de etanol içerisinde 48 saat bekletilerek insörtlü olarak kalıplanan numunelere, besleme stoku içerisinden çözündürmeyle bağlayıcı giderme işlemi uygulanmıştır. Bağlayıcı giderme işleminin ardından deney numuneleri, WC-Co (\%9) ve HSS malzemelerin termal özellikleri dikkate alınarak Tablo 7'de verilen şartlarda kontrol atmosferi altında $\left(\% 95 \mathrm{~N}_{2}\right.$ ve $\left.\% 5 \mathrm{H}_{2}\right)$ sinterlenmiştir.

Tablo 7. Deney tasarımı

\begin{tabular}{|c|c|c|c|c|c|}
\hline İnsört & Ara katman & Sinterleme Sicaklı̆̆ $1\left({ }^{\circ} \mathrm{C}\right)$ & $\begin{array}{c}\text { Ara katman } \\
\text { kalınlığ }(\mu \mathrm{m})\end{array}$ & $\begin{array}{l}\text { Sinterleme } \\
\text { Süresi (dak) }\end{array}$ & Deney No \\
\hline \multirow{19}{*}{ HSS } & \multirow{19}{*}{$\mathrm{Ni}$} & \multirow{9}{*}{1200} & 25 & 120 & 1 \\
\hline & & & 25 & 240 & 2 \\
\hline & & & 25 & 360 & 3 \\
\hline & & & 50 & 120 & 4 \\
\hline & & & 50 & 240 & 5 \\
\hline & & & 50 & 360 & 6 \\
\hline & & & 100 & 120 & 7 \\
\hline & & & 100 & 240 & 8 \\
\hline & & & 100 & 360 & 9 \\
\hline & & \multirow{9}{*}{1250} & 25 & 120 & 10 \\
\hline & & & 25 & 240 & 11 \\
\hline & & & 25 & 360 & 12 \\
\hline & & & 50 & 120 & 13 \\
\hline & & & 50 & 240 & 14 \\
\hline & & & 50 & 360 & 15 \\
\hline & & & 100 & 120 & 16 \\
\hline & & & 100 & 240 & 17 \\
\hline & & & 100 & 360 & 18 \\
\hline & & 1300 & 100 & 120 & 19 \\
\hline
\end{tabular}




\subsection{Mekanik Testler (Mechanical Tests)}

Sinterleme işleminden sonra insörtün dıştan merkeze doğru sertliği ölçülerek ortalamaları alınmıştır. Ayrıca, insört ve enjekte bölge arasındaki birleşme dayanımını incelemek için $50 \mathrm{kN}$ kapasiteli çekmebasma deney cihazında basma deneyi yapılmıştır. Bunun için Şekil 2'de görülen sistem kullanılmıştır. Birleşme bölgesinin çapı (D), ve kalınlığı (t) kullanılarak Eş.1 yardımıyla kesilen alan (A) hesaplandıktan sonra basma deneyinde elde edilen yük (F) kesilen alana (A) bölünmüşs (Eş.2) ve ara bölgenin kesme dayanımı $(\tau)$ hesaplanmıştır.

$\mathrm{A}=\mathrm{Dx} \pi \mathrm{xt}$

$\tau=\mathrm{F} / \mathrm{A}$

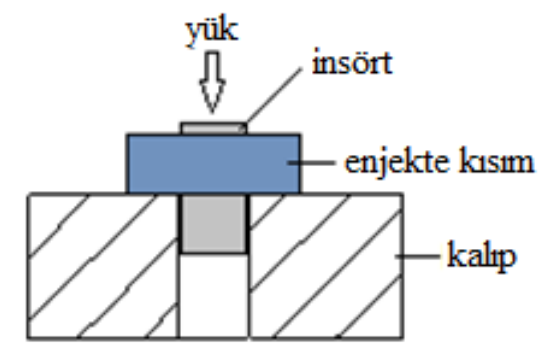

Şekil 2. Mekanik test sistemi

\section{SONUÇLAR VE TARTIŞMA (RESULTS AND DISCUSSION)}

\subsection{Sinterleme Sonrası Boyut Değişimi (Size Change After Sintering)}

Sinterleme işlemi sonrasında parçaların boyutları $0,01 \mathrm{~mm}$ hassasiyetinde mikrometre ile ölçülerek sıcaklık ve süreye bağlı olarak meydana gelen boyutsal değişimler yüzdesel olarak hesaplanmıştır ( Şekil $3)$.

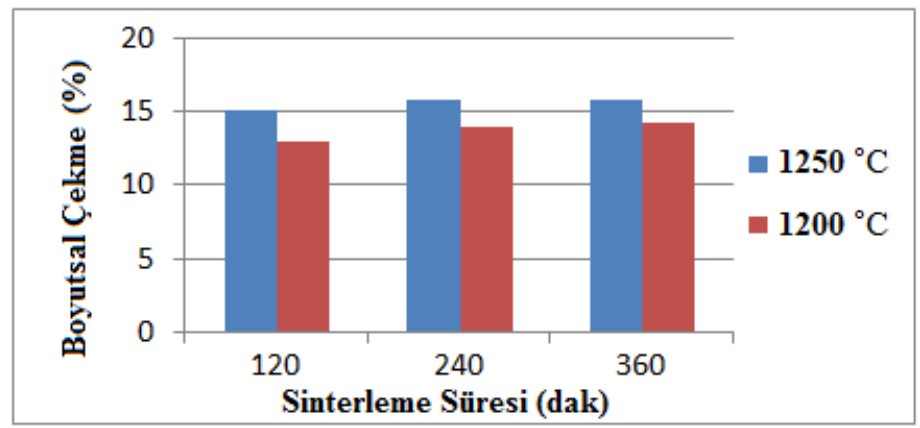

Şekil 3. Sinterleme sıcaklı̆̆ııın ve süresinin boyutsal çekmeye etkisi

Sicaklık ve süre arttıkça boyutsal çekme oranı da artmaktadır ve elde edilen en yüksek boyutsal çekme $1250{ }^{\circ} \mathrm{C}$ ve 360 dakikada üretilen parçalarda \%15,92 olarak ölçülmüştür (Şekil 3). Literatürde, WC-Co besleme stokunun boyutsal çekme miktarının \%14-\%15 olduğu ve sinterleme süresinin artmasıyla boyutsal çekmenin de arttı̆̆ belirtilmektedir [21-23]. Yaptığımız çalışmada elde edilen sonuçların literatürle uyumlu olduğu tespit edilmiştir.

\subsection{Sinterleme Sıcaklığının Etkisi (Effect of Sintering Temperature)}

WC-Co besleme stoku Co oranına bağlı olarak $1300-1600^{\circ} \mathrm{C}$ arasında ve $60-90 \mathrm{dk}$ süreyle sinterlenmektedir [23,24]. Sinterleme sicaklığını arttırmak yoğunluk, boyutsal çekme ve parça mukavemeti bakımından önemlidir. Ancak HSS insörtün termal özellikleri sinterleme sıcaklı̆̆ını etkilemektedir. Bu yüzden HSS insört kullanılarak kalıplanan parçalar WC-Co için literatürde belirtilen 
sicaklık değerlerinden daha düșük sıcaklıkta sinterlenmiștir. Buna rağmen $1300{ }^{\circ} \mathrm{C}$ de yapılan sinterleme işleminde HSS insört üzerinde erime meydana geldiği ve ara bölgede birleşme olmadığ görülmüştür (Şekil 4a, 4b). Bu sıcaklıkta HSS ile Ni katman arasında sıvı faz oluştuğu için insört üzerinde erime meydana geldiği düşünülmektedir. Simchi ve Petzoldt [25], Ni ara katman kullanarak WC-Co ve 316L paslanmaz çelik besleme stoklarından ko-enjeksiyonla elde ettikleri parçanın sinterleme davranışlarını araştırmışlardır. Ni katmanın ara yüzeyde sıvı film oluşturduğu ve bundan dolayı ara bölgedeki yapının erime sıcaklığının düştüğünü belirtmektedirler. Bununla birlikte Uhrenius ve diğerleri [26], Fe-Ni-Co-W$\mathrm{C}$ faz diyagramını oluşturarak erime sıcaklığının, bağlayıcı kompozisyonuna ve ağırlıç̧a yüzdesine bağlı olarak $1200{ }^{\circ} \mathrm{C}$ ile $1300{ }^{\circ} \mathrm{C}$ arasında değiştiğini belirtmektedirler. HSS insört kaplamasız olarak sinterlendiğinde üzerinde erime olmaması (Şekil 4c ) ve literatürden elde edilen bilgiler, HSS insörtün erimesi üzerinde en büyük etkenin Ni ara katman olduğunu göstermektedir.

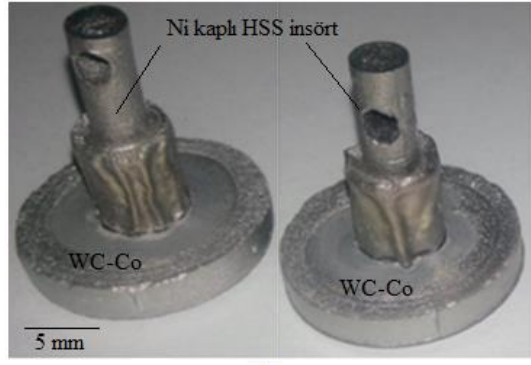

a)

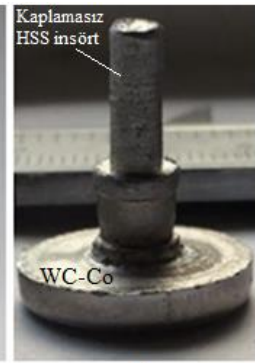

b)

Şekil 4. $1300^{\circ} \mathrm{C}$ de sinterlenen numuneler

(a: Ni kaplı HSS insört kullanılan numunler, b:kaplamasız HSS insört kullanılan numune)

$1250{ }^{\circ} \mathrm{C}$ sinterleme sıcaklığında yapılan deneylerde HSS insört erimemektedir ancak insört ve besleme stoku arasında yeterli birleşme sağlanamamıştır. $1250{ }^{\circ} \mathrm{C}$ ve 240 dakikada yapılan deneyde sinterleme sonrası HSS insört incelendiğinde enjekte bölgenin olduğu kısmın çapı 6,45 mm'den 6,2 mm'ye küçülmüştür (Şekil 5c). HSS ve WC arasında birleşme olabilmesi için arada yeterli basıncın da olması gerekmektedir. $1250{ }^{\circ} \mathrm{C}$ 'de HSS malzeme erimemektedir ancak yumuşadığı için enjekte bölgenin baskılaması sonucu çapı küçülmekte ve arada yeterli basınç oluşmamaktadır bu yüzden $1250{ }^{\circ} \mathrm{C}$ de birleşme olmamakta veya zayıf olmaktadır (Şekil $5 \mathrm{~b}$ ve $5 \mathrm{c}$ ) . $1200^{\circ} \mathrm{C}$ sıcaklıkta ise birleşme bakımından daha iyi sonuçlar elde edilmiştir. Yaptığımız çalışmada mekanik testler sonucu kırılan parçalar incelendiğinde Şekil 5a'da insört üzerinde WC tabakası görülmektedir. Bu durum kırılmanın WC tarafından olduğunu ve $1200{ }^{\circ} \mathrm{C}$ sicaklıkta insört ve enjekte bölge arasında birleşmenin sağlandığını göstermektedir. Sicaklık, basınç ve süre difüzyonu etkileyen önemli parametrelerdir ve farklı malzemelerin birleştirilmesinde ara bölgenin mukavemetini önemli ölçüde etkilemektedirler [27-30]. Johnson ve arkadaşları [19], iç içe geçen farklı malzemelerden parça üretilirken ara yüzeyde birleşme için yeterli basıncın olması gerektiğini belirtmiş̧lerdir. Sinterleme işleminde insört ve besleme stoku arasında oluşan basınç enjekte kısmın boyutsal çekmesi sonucu doğal olarak oluşmaktadır. Sıcaklık ve süre arttıkça insörtün yumuşaması ara bölgede basıncın azalmasına ve ara bölgedeki mukavemet değerinin düşmesine neden olmaktadır.

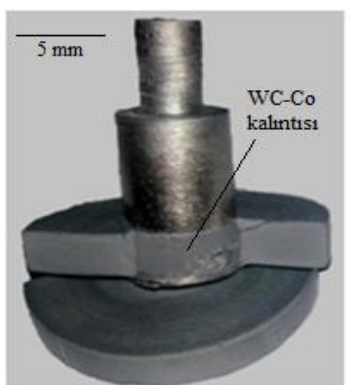

a)

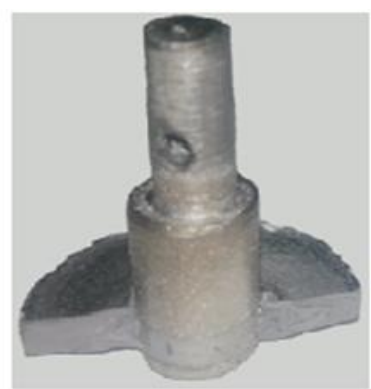

b)

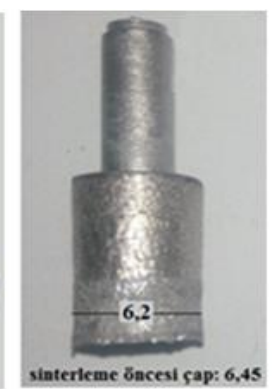

c)

Şekil 5. $100 \mu \mathrm{m}$ Ni ara katman kullanılan parçaların mekanik testler sonucu kırık görüntüleri a) $1200{ }^{\circ} \mathrm{C}$, $240 \mathrm{dak}$ b) $1250{ }^{\circ} \mathrm{C}, 120 \mathrm{dak}$ c) $1250{ }^{\circ} \mathrm{C}, 240 \mathrm{dak}$ 


\subsection{Ni Difüzyonu (Ni Diffusion)}

$\mathrm{Ni}$ ara katman kullanılarak $1200{ }^{\circ} \mathrm{C}$ sinterleme sıcaklığında enjekte bölge ile HSS insört arasında birleşme sağlanmıştır (Şekil 6). EDS analizlerinde Şekil 6'da görülen 5. noktadaki Ni miktarı \% 0.827 olarak ölçülmüştür. Bu durum Ni ara katmanın WC-Co (\%9) tarafina doğru yaklaşık $300 \mu \mathrm{m}$ difüzyon olduğunu göstermektedir. WC-Co tarafinda, 5. noktadan ara katman sınırına kadar Ni difüzyonu \%8.481'e kadar artmaktadır. Ni yüksek sicaklıklarda korozyon direncine ve mükemmel plastisiteye sahip ara malzemesidir [31] ve $\mathrm{Fe}$ ve Co içerisinde katı çözünürlüğ̈̈ iyidir [32,33]. Bu nedenle WC besleme stokunun içerisinde $\% 9$ oranında Co bulunması $\mathrm{Ni}$ ara katmanın enjekte kısma doğru difüzyonunu kolaylaştırmaktadır.

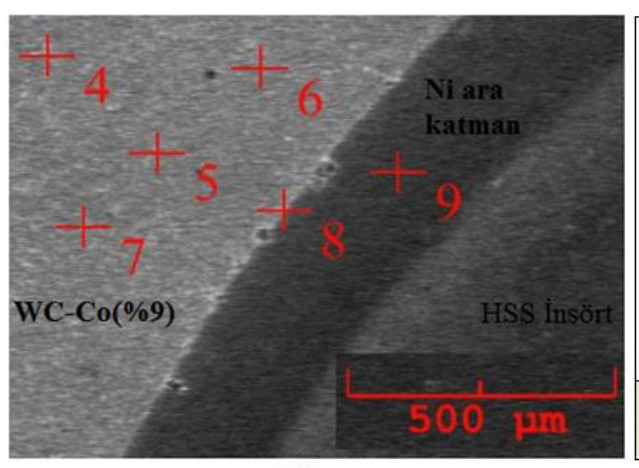

a)

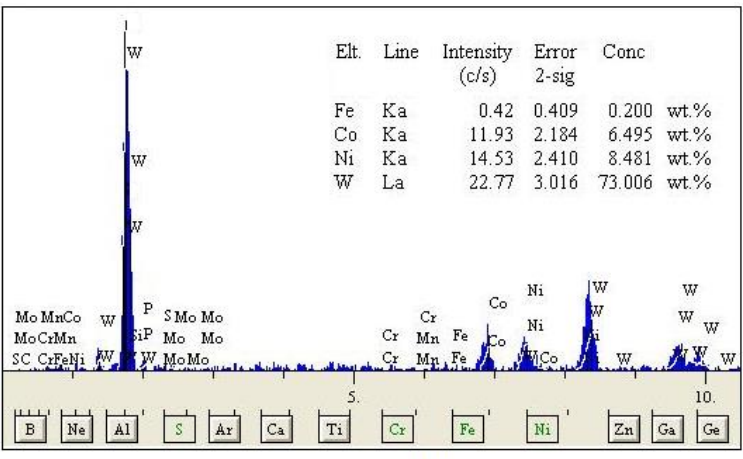

b)

Şekil 6. $1200{ }^{\circ} \mathrm{C} 240$ dakikada yapılan deney sonrası WC ve HSS arasındaki Ni geçişi (a: EDS analizi yapllan bölge, b: 8. Noktadaki analiz sonucu)

\subsection{Birleşme Bölgesinin Kesme Mukavemeti (Shear Strength of İntermediate Zone)}

$1200{ }^{\circ} \mathrm{C}$ sıcaklıkta farklı sürelerde sinterlenen parçalar için elde edilen kesme dayanımı değerleri grafik haline dönüştürülmüştür (Şekil 7). Grafik incelendiğinde ara katman kalınlığının artmasıyla ve sinterleme süresinin azalmasıyla kesme mukavemeti artmaktadır. Üretilen parçaların dış kısmı WC-\%9Co iç kısmı HSS malzemeden oluşmaktadır. WC-\%9Co malzemenin termal genleşme katsayısı $\left(5,7-5,9 \times 10^{-6} / \mathrm{K}\right) \mathrm{HSS}$ malzemenin termal genleşme katsayısından $\left(11,5-12,9 \times 10^{-6} / \mathrm{K}\right)$ daha düşük olduğu için soğuma esnasında iç kısımdaki HSS malzemenin daha fazla daraldığı ve bundan dolayı ara bölgede gerilmelerin arttığı söylenebilir. Kaplama kalınlığının artmasıyla soğuma esnasında termal genleşmeden dolayı malzemeler arasında meydana gelen ölçüsel farklılık daha iyi tolere edilerek ortaya çıkan gerilmelerin azaldığ 1 ve bundan dolayı kesme dayanımının arttığı düşünülmektedir. $1200{ }^{\circ} \mathrm{C}$ sicaklıkta $100 \mu \mathrm{m} \mathrm{Ni}$ ara katman kullanılan numunelerde 120 dakika sinterleme süresiyle ara bölgede elde edilen en yüksek kesme dayanımı $114 \mathrm{MPa}$ 'dır. En düşük kesme dayanımı ise $25 \mu \mathrm{m}$ Ni ara katman kullanılarak 360 dakika sinterlenen numunelerde $23 \mathrm{MPa}$ olarak elde edilmiştir. İTEK yöntemi yeni olarak geliştirilen bir yöntem olduğu için bu yöntemle WC-Co ve çelik malzemelerin birleştirilmesi konusunda yapılan çalışmalar sınırlıdır. Bu nedenle yaptığımız çalışmada elde ettiğimiz kesme dayanımı değerleri literatürde difüzyon kaynağıyla elde edilen verilerle kıyaslanmıştır. Literatürde difüzyon kaynağıyla birleştirilen WC-Co/çelik malzemelerin ara bölgedeki kesme dayanımı değerleri işlem parametrelerine bağlı olarak 45-620 MPa arasında değiştiği görülmüş̧ür [27,34,35]. İTEK yöntemiyle bu çalışmada elde edilen en yüksek mukavemet değeri difüzyon kaynağıyla elde edilen birleştirmelerin mukavemet değerleriyle örtüşmektedir. Grafik incelendiğinde $1200{ }^{\circ} \mathrm{C}$ sinterleme sıcaklığında süre arttıkça ara bölgenin kesme dayanımı azalmaktadır. İTEK yönteminde malzemelerin sinterleme esnasında birleştirilmesi difüzyon kaynağına benzerdir. Bu nedenle difüzyon kaynağında oluğu gibi [27-30] iki malzeme İTEK yöntemiyle birleştirilirken ara bölgenin mukavemeti bakımından basıncın önemli bir parametre olduğu ifade edilebilir. Yapılan çalışmada $1200{ }^{\circ} \mathrm{C}$ sıcaklıkta süre arttıkça HSS insört yumuşadığı için ara bölgede oluşan basıncın düştüğü ve bu nedenle süre arttıkça kesme dayanımının azaldığı düşünülmektedir. 100 $\mu \mathrm{m}$ ara katman kullanılarak yapılan deneylerde sinterleme süresi 120 dakikadan 240 dakikaya çıktığında kesme dayanımı keskin bir şekilde azaldığı Şekil 7'de görülmektedir. $50 \mu \mathrm{m}$ ve $25 \mu \mathrm{m}$ ara katman kullanılan deneylerde ise değişim, $100 \mu \mathrm{m}$ 'na göre daha az gerçekleşmiştir. Süre arttıkça kesme 
dayanımının düşmesinin temel nedeni HSS insörtün ve üzerindeki nikel kaplamanın yumuşamasıyla birleştirme için gerekli olan basıncın azalmasıdır. $100 \mu \mathrm{m}$ nikel kaplama kullanılan deneylerde 120 dakika sinterleme süresinden 240 dakikaya çıkıldığında ara bölgede kaplama kalınlığına bağlı olarak yumuşayan bölgenin kalınlığının artmasıyla basıncın daha fazla azaldığı ve bundan dolayı $50 \mu \mathrm{m}$ ve 25 $\mu \mathrm{m}$ kalınlığa göre kesme dayanımında keskin bir azalma meydana geldiği söylenilebilir.

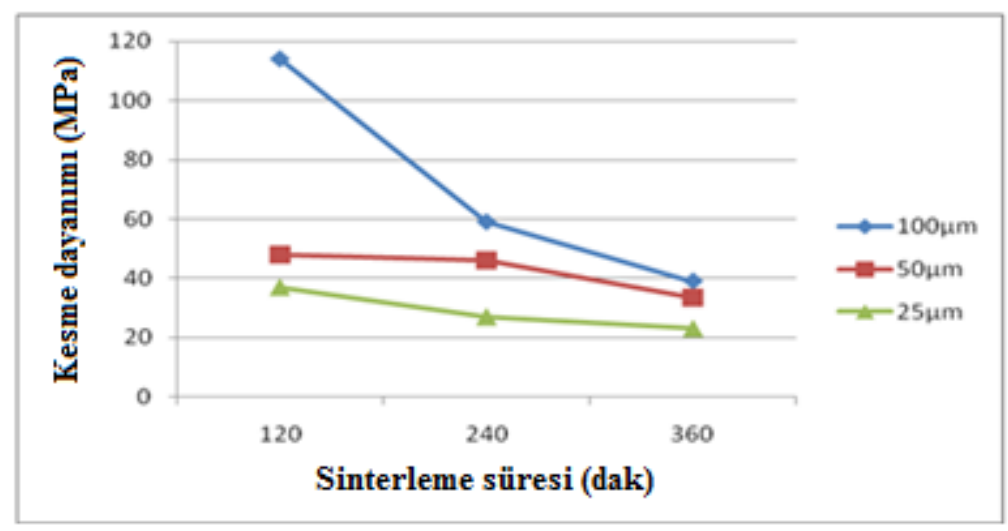

Şekil 7. $1200^{\circ} \mathrm{C}^{\prime}$ de sinterleme süresinin kesme dayanımına etkisi

\subsection{Sinterleme Sonrası HSS İnsörtün Sertliği (HSS Inserts Hardness After Sintering)}

Sinterleme işleminden sonra M2 HSS insörtün sertlik değerleri ölçülmüş̧ür (Şekil 8). Elde edilen sertlik değerleri 49-50 HRc aralığındadır. Bu malzeme için 1190-1230 ${ }^{\circ} \mathrm{C}$ arasındaki sıcaklıkta 300-350 saniye bekletilerek yapılan 1sıl işlemle elde edilebilecek setlik değerleri kataloğunda 62-65 HRc arasında olduğu belirtilmektedir. Ancak sinterleme süresi uzun olduğu ve malzeme firında yavaş soğutulduğu için katalog değerlerinden daha düşük sertlikler elde edilmiştir.

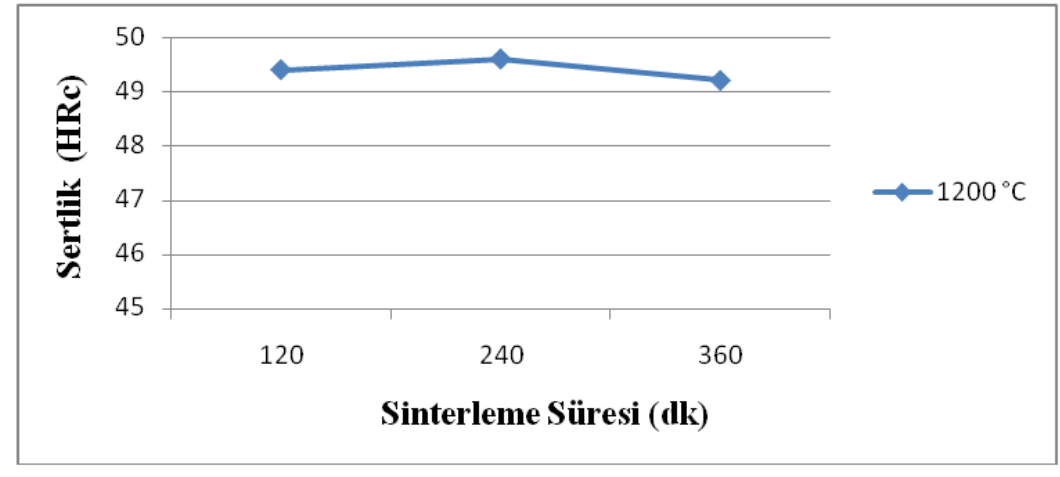

Şekil 8. Sinterleme sonrası HSS insörtün sertliği

\section{SONUÇLAR (CONCLUSION)}

Nikel ara katman kullanılarak İTEK yöntemiyle WC-Co/HSS kompozit parça üretiminin araştırıldığı bu çalışmada elde edilen sonuçlar aşağıda özetlenmiştir.

- İTEK yöntemi kullanılarak içi HSS dış kısmı WC olan parça üretilebilmiştir.

- Sinterleme sıcaklığı ve süresi arttıkça boyutsal çekme oranı artmaktadır ve $1250{ }^{\circ} \mathrm{C}$ ve 360 dakikada enjekte kısımda (WC-Co) en yüksek boyutsal çekme \%15,92 olarak bulunmuştur.

- En yüksek kesme mukavemeti $1200{ }^{\circ} \mathrm{C}$ sicaklık ve 120 dakika sinterleme süresiyle, $100 \mu \mathrm{m} \mathrm{Ni}$ ara katman kullanılan numunede $114 \mathrm{MPa}$ olarak elde edilmiştir. 
- $1200{ }^{\circ} \mathrm{C}^{\prime}$ de sinterleme süresinin artmasıyla ve kaplama kalınlığının azalmasıyla kesme mukavemeti düşmektedir. En düşük kesme mukavemeti 360 dakika sinterlenen $25 \mu \mathrm{m}$ Ni ara katman kullanılan numunede $23 \mathrm{MPa}$ olarak elde edilmiştir.

- $1300{ }^{\circ} \mathrm{C}$ de yapılan sinterleme işleminde HSS insört üzerinde erime meydana gelmekte ve WC$\mathrm{Co} / \mathrm{HSS}$ ara bölgesinde birleşme olmamaktadır.

- $1250{ }^{\circ} \mathrm{C}$ 'de yapılan deneylerde HSS malzeme erimemektedir ancak bu sıcaklıkta yumuşadığı için enjekte bölgenin baskılaması sonucu insört çapı küçülmektedir. Bundan dolayı ara bölgede difüzyon için gerekli basınç azaldığı için mukavemet açısından yeterli düzeyde birleşme elde edilememiştir.

- $1200{ }^{\circ} \mathrm{C}$ sicaklıkta ve 240 dakikada yapılan sinterlemede Ni ara katman WC-Co tarafina doğru 300 $\mu \mathrm{m}$ difüzyon olmaktadır.

\section{TEŞEKKÜR (ACKNOWLEDGMENTS)}

Bu çalışmaya destek sağlayan 115M437 kodlu proje kapsamında TÜBİTAK’a ve 07/2016-21 kodlu BAP projesi kapsamında Gazi Üniversitesi, Bilimsel Araştırma Proje Birimine teşekkür ederiz.

\section{KAYNAKLAR (REFERENCES)}

[1] German, R.M. and Bose, A. (1997). Injection Molding of Metals and Ceramics (First edition). Metal Powder Industries Federation. New Jersey: Princeton, 5-280.

[2] Safarian, A., Subaşi, M., Karataş, Ç., "Reducing debinding time in thick components fabricated by powder injection molding", International Journal of Materials Research, Vol. 106, No. 5, pp.527-531., 2015.

[3] Karataş, Ç., Sarıtaş, S., "Rheological Properties 0f Mixed GasWater Atomized Stainless Steel Powder MIM Feedstock" The International Journal of Powder Metallurgy, 37, No.8 (3944), 2001.

[4] Karataş, Ç., Sarıtaş, S., "Toz Enjeksiyon Kalıplama: Bir Yüksek Teknoloji imalat Metodu” Gazi Ün. Mühendislik Mimarlık Fakültesi Dergisi, 13, (2),(193), 1998.

[5] Safarian, A., Subaşi, M., Karataş, Ç., "The effect of sintering parameters on diffusion bonding of 316L stainless steel in inserted metal injection molding, Int J Adv Manuf Technol, 89, 2165$2173,2017$.

[6] Brookes, K.J.A., World Directory and Handbook of Hardmetals, 4th ed., International Carbide Data, Hertfordshire, UK, pp. 47-59.,1987.

[7] Parasiris, A., Hartwig, K.T., and Srinivasan M.N., : Scripta Mater., vol. 42, pp. 875-80., 2000

[8] Wang, X., Fang, Z.Z., and Sohn, H.Y., “"Grain growth during the early stage of sintering of nanosized WC-Co powder", Int. J. Refract. Met. Hard Mater., vol. 26, pp. 232-241., 2008.

[9] Nowacki, J., Kawiak, M., "Tensions and deformations of WC - CO cermets and 17-4 PH steel vacuum brazed joints", Journal of Mater. Processing Technology, 686, 1-6.,2003.

[10] Northrop I. T., "The joining of tungsten carbide hardmetal to steel”, J. S. Afr. Inst. Min. Metall., 87:125-35, 1987.

[11] Naylor, W.P., Introduction to Metal-Ceramic Technology, Quintessence Publishing Co.Inc., Chicago, 1992

[12] Passerone A., and Muolo, M.L., "Metal-Ceramic Interfaces: Wetting and Joining Processes", Int. J. Mater. Prod. Technol., 20(5/6), p 420-439, 2004. 
[13] Atabaki, M. M., "Recent Progress In Joining Of Ceramic Powder Metallurgy Products To Metals", Association of Metall. Engineers of Serbia, Vol 16 (4), p. 255-268, 2010.

[14] Cai, P. Z., Green D. J., and Messing, G. L., "Constrained Densification of Alumina/Zirconia Hybrid Laminates, I: Experimental Observations of Precessing Defects” J. Amer. Ceram. Soc. 80, 1929-39, 1997.

[15] Heaney, D. F., Sur1, P., German, R. M., "Defect-free sintering of two material powder injection molded components", Journal Of Materials Science, 38, 4869 - 4874, 2003.

[16] Zhonga, Z., Hinokib, T., Kohyamab, A., "Effect of holding time on the microstructure and strength of tungsten/ferritic steel joints diffusion bonded with a nickel interlayer", Materials Science and Engineering, A 518, 167-173, 2009.

[17] Zhang, J.X., Chandel, R.S., Chen, Y.Z., Seow, H.P., "Effect of residual stress on the strength of an alumina-steel joint by partial transient liquid phase (PTLP) brazing", Journal of Materials Processing Technology, 122, 220-225, 2002.

[18] Chen, H., Feng, K., Xiong, J., Guo., Z., "Characterization and stress relaxation of the functionally graded WC-Co/Ni component/stainless steel joint", Journal of Alloys and Compounds, 557, 18 $22,2013$.

[19] Johnson, J.L., Tan, L.K., Suri, P. and German, R.M., "Design guidelines for processing bimaterial components via powder-injection molding". The Journal of the Minerals, Metals \& Materials Society, 55(10), 30-34., 2003

[20] Ruh, A., Piotter, V., Plewa, K., Haußelt, J., "Effects of material improvement and injection moulding tool design on the movability of sintered two-component micro parts", Microsystem Technologies, 16(11):1989-1994 $\cdot(2010)$

[21] Baojun, Z., Xuanhui, Q., Ying, T., "Powder injection molding of WC-8\%Co tungsten cemented carbide”, International Journal of Refractory Metals \& Hard Materials, 20, 389-394, 2002.

[22] Sun, Y., Su, W., Yang, H., Ruan, J., "Effects of WC particle size on sintering behaviour and mechanical properties of coarse grained WC-8Co cemented carbides fabricated by unmilled composite powders", Ceramics International, 41,14482-14491, 2015.

[23] Heng, S.Y., Muhamad, N., Sulongn, A.B., Fayyaz, A., Yulis, S., Amin, M., "Effect of sintering temperature on the mechanical and physica lproperties of WC-10\% Co through micro-powder injection molding(mPIM)", Ceramics International, 39, 4457-446, 2013.

[24] Eso, O., Fang, Z., Griffo, A., "Liquid phase sintering of functionally graded WC-Co composites", International Journal of Refractory Metals \& Hard Materials, 23, 233-241, 2005.

[25] Simchi A. and Petzoldt F., "Cosintering of Powder Injection Molding Parts Madefrom Ultrafine WC-Co and 316L Stainless Steel Powders for Fabrication of Novel Composite Structures", Metallurgical And Materials Transactions, V 41A, 234, 2010.

[26] Uhrenius, B., Pastor, H. and Pauty, E.,: Int. J. Refract. Met. Hard Mater., vol. 15, pp. 139-49, 1997.

[27] Chen, H., Feng, K., Wei, S., Xiong, J., Guo Z., Wang, H., "Microstructure and properties of WC$\mathrm{Co} / 3 \mathrm{Cr} 13$ joints brazed using Ni electroplated interlayer" Int. Journal of Refractory Metals and Hard Materials, 33, 70-74,2012

[28] Jadoon, A.K., Ralph, B., Hornsby, P.R., "Metal to ceramic joining via a metallic interlayer bonding technique", Journal of Materials Processing Technology, 152, 257-265, 2004 
[29] AYDIN, M., "Gözenekli Seramik Malzeme İle Paslanmaz Çeliğin Difüzyon Kaynak Yöntemiyle Birleştirilmesi”, Gazi Üniv. Müh. Mim. Fak. Der., Cilt 23, No 3, 595-599, 2008.

[30] Kurt, A., Uygur, İ., ve Ateş, H., "Effect of Temperature on Weldability of Powder Metal Parts Joined by Diffusion Welding", Materials Science Forum, 546-549(667-670), 2007.

[31] Zhang, J., Xiao, Y., Luo, G.Q., Shen, Q., Zhang, LM., "Effect of Ni interlayer on strength and microstructure of diffusion-bonded Mo/Cu joints", Mater Lett, 66:113-6, 2012.

[32] Prince, A., Okamoto, H., "Handbook of ternary alloy phase diagrams". Materials Park: ASM International, 1995.

[33] Fernandes, C.M., Seno, A.M.R., "Cemented carbide phase diagrams: a review" Int J Refract. Met. Hard. Mater., 29:405-18, 2011.

[34] Barrena, M.I., Gomez J.M., Salazar, L., Matesanz "Interfacial microstructure and mechanical strength of $\mathrm{WC}-\mathrm{Co} / 90 \mathrm{MnCrV} 8$ cold work tool steel diffusion bonded joint with $\mathrm{Cu} / \mathrm{Ni}$ electroplated interlayer", Materials and Design, 3, 3389-3394, 2010

[35] Feng, K., Chen, H., Xiong, J., Guo, Z., "Inves. on diffusion bonding of functionally graded WCCo/Ni composite and stainless steel”, Mater. and Des., 46, 622-626, 2013. 